\title{
Does Provider Gender Affect the Quality of Primary Care?
}

\author{
Jeffrey L. Jackson, MD, MPH, Amy Farkas, MD, MSc, and Cecilia Scholcoff, MD, MPH
}

BACKGROUND: Women providers have a more patientcentered communication style than men, and some studies have found women primary care providers are more likely to meet quality performance measures.

OBJECTIVE: To explore gender differences in the quality of primary care process and outcome measures.

DESIGN: Retrospective analysis of primary care performance data from 1 year (2018-2019).

PARTICIPANTS: A total of 586 primary care providers (311 women and 275 men) who cared for 241,428 primary care patients at 96 primary care clinics at 8 Veterans Affairs (VA) medical centers.

MAIN MEASURES: Our primary outcome was a composite quality measure that averaged all thirty-four primary care performance measures that assessed performance in cancer screening, diabetes care, cardiovascular care, tobacco counseling, risky alcohol screening, immunizations, HIV testing, opiate care, and continuity. Our secondary outcomes were performance on each of the 34 measures.

KEY RESULTS: There was no difference in the average performance on our composite measure between men and women $(75.8 \%$ vs. $76.6 \%, p=0.17)$. Among the 34 primary care quality measures collected, there was no difference between male and female providers' performance. Using a more conservative cut-point, women were more likely to screen at-risk diabetic patients for hypoglycemia and document follow-up on risky alcohol behavior noted during patient check-in. These differences were clinically small and likely due to chance, given the multiple measures evaluated in this study.

CONCLUSIONS: We found little evidence of difference in the performance on primary care quality measures between male and female providers.

J Gen Intern Med 35(7):2094-8

DOI: $10.1007 / \mathrm{s} 11606-020-05796-0$

(c) Society of General Internal Medicine (This is a U.S. government work and not under copyright protection in the U.S.; foreign copyright protection may apply) 2020

$\mathrm{W}$ omen providers have a more patient-centered communication style than men ${ }^{1,2}$ and are more likely to provide counseling about preventive services, ${ }^{3-10}$ including diet and exercise. ${ }^{11}$ However, this difference does not result in improved

Received November 13, 2019

Accepted March 11, 2020

Published online April 6, 2020 diabetes or blood pressure control or the use of appropriate cardiovascular risk-modifying medications for patients cared for by women providers. ${ }^{11}$ Some studies, ${ }^{10,12}$ but not all, ${ }^{13,14}$ have found women cared for by women are more likely to have undergone pap smears and mammograms. Beyond genderspecific cancer screening, additional studies, ${ }^{15,16}$ but not all, ${ }^{11,}$

13, 17 have found that women do better on other primary care quality measures. If women primary care providers deliver superior care compared with men, there could be implications for patients selecting a primary care provider as well as for healthcare systems determining workforce composition.

Most of the studies examining gender differences in primary care quality are decades old, ${ }^{3-8,12}$ from an era when few practices had electronic health records (EHRs), clinical reminders, ${ }^{18}$ patient-centered medical homes (PCMH), or incentivized performance based on meeting quality benchmarks. ${ }^{19}$ From 2004 until 2017, the percentage of office-based physicians with electronic health record systems increased from 21 to $86 \%,{ }^{20}$ and most have clinical registries or clinical reminders. In addition, the number of PCMH-recognized medical practices is now over $13,000 .^{21}$ Consequently, our study purpose was to explore gender differences in the quality of primary care process and outcome measures in a modern US cohort.

\section{METHODS}

Study participants were primary care providers (physicians, nurse practitioners, and physician assistants) from 96 primary clinics at 8 midwestern Veterans Health Administration (VHA) medical centers. The VHA routinely collects and provides quarterly feedback to primary care providers on a number of quality measures. This quarterly feedback comes in two forms, an email with their performance report and placing the individual reports in the providers' clinic mailboxes. The report is an Excel spreadsheet that gives the providers' performance on the performance measures, with benchmarking against VA regional and national performance numbers. In addition, the VHA EHR provides patient-specific clinical reminders to providers about the need to perform these health measures. These measures were developed by the national VHA primary care quality assessment team and include a combination of Healthcare Effectiveness Data and Information Set (HEDIS) ${ }^{22}$ measures of primary care quality (though the VA uses the EHR, while HEDIS is claims based) and nonHEDIS measures. The HEDIS measures included: cancer screening (colorectal, mammography, and cervical); diabetes 
care (glycated hemoglobin $\left(\mathrm{HbA}_{1 \mathrm{c}}\right.$ level) less than $9.0 \%$ blood pressure less than $140 / 90 \mathrm{mmHg}$, diabetes control at goal, retinal examination, on moderate dose of statin); cardiovascular care (blood pressure less than 140/90 $\mathrm{mmHg}$; use of moderate-dose statins in patients with known atherosclerotic coronary artery disease; post-myocardial infarction use of $\beta$ blockers; use of angiotensin-converting enzyme inhibitors in patients with congestive heart failure), tobacco and risky alcohol use screening, regular follow-up appointment (within 18 months), immunization rates (influenza, PCV13, PPSV23, and Tdap). Previous studies have shown good reliability and validity for these quality measures. ${ }^{23}$ Additional non-HEDIS measures included post-myocardial infarction use of aspirin, diabetic screening for hypoglycemia, foot examination performance and podiatry referral for diabetic patients, HIV testing offered, opioid urine screen, and opioid consent. These nonHEDIS care indicators measure interventions that have been shown to be associated with reduced mortality ${ }^{24-28}$ and improved quality of life. ${ }^{29}$ Some of these measures (such as cancer screening) are based on performance within the past year; others (such as percentage of patients at goal for diabetes care) are based on the previous 3 months. Not all HEDIS measures are collected by the VA, for example, coordination of care for substance abuse disorders.

Each of these measures is based on the clinical indication (e.g., being over 50 for colorectal screening), and the number of patients in each panel that were eligible for each measure varied. Quality measures for which providers had no eligible patients (for example, no women in the panel eligible for mammography) were excluded for that provider. Performance scores for each clinical indicator were calculated as the ratio of the number of provider panel patients who met the indicator over the number of patients who are eligible for that measure.

We extracted performance data from primary care providers at 8 VA medical centers - Clement J. Zablocki VAMC (Milwaukee, WI), Iron Mountain (Jesse Brown VAMC) (Chicago, IL), Hines VAMC (Chicago, IL), James A. Lovell Federal Health Care Center (North Chicago, IL), Oscar G. Johnson VAMC (Iron Mountain, MI), Tomah VAMC (Tomah, WI), VA Illiana Health Care Center (Danville, IL), and William S. Middleton VAMC (Madison, WI) - for 1 year (4 quarters) between 1 March 2018 and 1 March 2019. For each provider, the average value over the four quarters was calculated for each measure.

Provider-level data included gender, year of graduation from training, type of provider (physician, nurse practitioner, physician assistant), status (trainee or staff), number of patients assigned to the provider, which medical center and specific clinic the provider works in, whether that center was an academic medical center (affiliated with a medical school and residency training program), and whether the clinic was in a rural or urban setting (defined as a county with an urban nucleus of 50,000 or more people). We excluded providers who had less than 25 total patients in their panel.

While we had no patient-level data, we extracted from the electronic health record aggregate data about patients seen in these clinics, such as their age, gender, and race. Our primary outcome was a composite quality of healthcare, based on averaging the performance on all measures for each provider, with each measure given equal weight. ${ }^{30}$ Secondary outcomes were the performance for each individual quality indicator. To assess the impact of gender, we used multivariable regression models with adjustment for clustering by site, with HuberWhite robust variances. Covariates included years since graduation, type of provider (MD or DO vs. NP or PA), and provider status (trainee vs. staff), and the number of patients in the panel was included as covariates. All analyses were performed using Stata (v 15.1, College Station, TX), and all testing was 2-sided with the $p$ value adjusted to $p=0.003$ for multiple comparisons using the false discovery rate test. ${ }^{31}$ In addition, we analyzed for differences between types of provider (MD vs. NP vs. PA). This project was approved by our local IRB.

\section{RESULTS}

There were 586 primary care providers (311 women and 275 men) who cared for 241,428 primary care patients (Table 1). The number of primary care providers varied at the 8 medical centers, ranging from 26 to 185 . The majority of providers were physicians $(81 \%, n=473)$ with 100 nurse practitioners and 13 physician assistants. Among the 586 providers, 370 (63\%) were staff and 216 were medicine residents providing patient care in their continuity clinics. Forty-three of the clinics

Table 1 Provider Characteristics

\begin{tabular}{|c|c|c|c|c|}
\hline Characteristics & $\begin{array}{l}\text { Overall } \\
(n=586)\end{array}$ & $\begin{array}{l}\text { Male } \\
(n=275)\end{array}$ & $\begin{array}{l}\text { Female } \\
(n=311)\end{array}$ & $p$ value \\
\hline Physician & $473(81 \%)$ & $255(93 \%)$ & $218(70 \%)$ & $<0.0005$ \\
\hline Nurse practitioner & $100(17 \%)$ & $16(6 \%)$ & $84(27 \%)$ & \\
\hline Physician's assistant & $13(2 \%)$ & $4(1 \%)$ & $9(3 \%)$ & \\
\hline Staff panel size, mean (range) & $621(26-1292)$ & $657(33-1292)$ & $600(26-1218)$ & 0.12 \\
\hline Trainee panel size, mean (range) & $54(25-152)$ & $55(25-83)$ & $52(27-152)$ & 0.12 \\
\hline Academic practice & $357(61 \%)$ & $194(71 \%)$ & $163(52 \%)$ & $<0.0005$ \\
\hline Staff & $370(63 \%)$ & $138(50 \%)$ & $232(75 \%)$ & $<0.0005$ \\
\hline Trainee & $216(37 \%)$ & $137(50 \%)$ & $79(25 \%)$ & \\
\hline Rural practice & $60(10 \%)$ & $17(6 \%)$ & $43(14 \%)$ & 0.004 \\
\hline Years since graduation from medical school, mean (range) & $10.4(1-48)$ & $10.2(1-48)$ & $10.9(1-37)$ & 0.42 \\
\hline
\end{tabular}


were rural and 53 were in urban areas. Staff providers averaged 621 patients in their panels with no difference in panel size by provider gender $(p=0.12)$. While trainee panels were smaller (mean $=54$ ), there was also no gender differences in this group $(p=0.11)$. Staff providers averaged 17.4 years since graduation from medical, nursing, or physician assistant school, with male providers having nearly 5 years more experience than female providers $(p<0.0001)$.

The average age among the 241,428 primary care patients was 64.4 years in age and most, $92.8 \%(n=224,149)$, were male. Male patients were older than females (65.5 vs. 50.7, $p<0.0005)$. The majority of clinic patients were white (83.7\%), with the majority of the remaining patients being African-American (14.3\%).

There were 34 primary care quality measures analyzed for this paper (Table 2). The number of patients eligible for the screens varied from 6723 (the number with a history of myocardial infarction) to the entire population (eligible for annual alcohol screen). There was no difference in the composite quality score between male and female primary care providers $(75.8 \%$ vs. $76.6 \%, p=0.17)$. Among the secondary outcomes, there were no differences in any measures, with no differences in cancer screening rates (colorectal, breast, and cervical cancer), cardiovascular disease measures (prescribed statins, post-myocardial infarction prescribed aspirin or betablockers, blood pressure control, screening for abdominal aneurysms). For diabetic measures, there was no difference in blood pressure control, achieving an A1c $<9 \%$, achieving patient-specific A1c goal, having retinal or foot examinations, receiving a podiatry referral, or screening for hypoglycemia. There was no difference in counseling for tobacco use or screening for risky alcohol consumption. There were no differences in immunization rates (influenza, pneumonia (PSV23, Prevnar 13), or tetanus-diptheriae). There was no

Table 2 Comparison of Percentage of Providers Meeting Primary Care Performance Measures by Gender

\begin{tabular}{|c|c|c|c|c|}
\hline Quality measures & Eligible patients & Male provider & Female provider & Adjusted $\boldsymbol{p}$ value* \\
\hline Composite outcome (SD) & 241,428 & $75.8 \%(5.6)$ & $76.6 \%(5.3)$ & 0.17 \\
\hline \multicolumn{5}{|l|}{ Cancer screening } \\
\hline Colorectal CA screen (SD) & 120,894 & $73.2 \%(11.6)$ & $73.0 \%(12.2)$ & 0.76 \\
\hline Mammogram screen age 52-74 (SD) & 9993 & $83.7 \%(19.8)$ & $79.4 \%(16.2)$ & 0.44 \\
\hline Mammogram screen age $40+(\mathrm{SD})$ & 7677 & $73.8 \%(21.7)$ & $69.3 \%(17.4)$ & 0.36 \\
\hline Cervical cancer screening (SD) & 12,377 & $73.5 \%(22.5)$ & $72.3 \%(18.2)$ & 0.66 \\
\hline \multicolumn{5}{|l|}{ Cardiovascular care } \\
\hline Abdominal aortic aneurysm screening (SD) & 49,821 & $79.7 \%(15.6)$ & $79.5 \%(15.9)$ & 0.60 \\
\hline CVD on moderate-dose statin (SD) & 35,792 & $75.4 \%(13.1)$ & $74.2 \%(12.9)$ & 0.55 \\
\hline \multicolumn{5}{|l|}{ History of myocardial infarction (SD) } \\
\hline On ASA & 6723 & $88.2 \%(16.1)$ & $88.6 \%(13.1)$ & 0.60 \\
\hline On beta-blocker & 6723 & $86.3 \%(14.4)$ & $87.0 \%(13.7)$ & 0.79 \\
\hline CHF on ACE I or ARB (SD) & 8273 & $83.6 \%(16.5)$ & $82.6(15.3)$ & 0.41 \\
\hline HTN BP < 139/89 age $18-59(\mathrm{SD})$ & 58,573 & $64.2 \%(12.0)$ & $66.0 \%(11.2)$ & 0.32 \\
\hline HTN BP $<149 / 89$ age $60-85$ (SD) & 68,759 & $80.6 \%(7.3)$ & $81.2 \%(7.6)$ & 0.99 \\
\hline HTN BP $<149 / 89$ (all ages) $(\mathrm{SD})$ & 127,332 & $77.2 \%(8.3)$ & $77.1 \%(8.1)$ & 0.89 \\
\hline \multicolumn{5}{|l|}{ Diabetes care } \\
\hline $\mathrm{BP}<140 / 90(\mathrm{SD})$ & 43,292 & $\begin{array}{l}72.4 \% \\
(9.4)\end{array}$ & $72.7 \%(9.0)$ & 0.67 \\
\hline $\mathrm{HbA} 1 \mathrm{c} \leq 9(\mathrm{SD})$ & 43,203 & $\begin{array}{l}78.6 \% \\
(9.3)\end{array}$ & $80.0 \%(9.0)$ & 0.12 \\
\hline A1C at goal (SD) & 60,118 & $86.1 \%(15.9)$ & $88.0 \%(13.7)$ & 0.50 \\
\hline Hypoglycemia screen performed (SD) & 7848 & $84.0 \%(18.6)$ & $87.7 \%(15.2)$ & 0.006 \\
\hline On moderate-dose statin (SD) & 26,137 & $72.9 \%(13.7)$ & $70.0 \%(12.1)$ & 0.09 \\
\hline Retinal exam performed (SD) & 43,291 & $76.4 \%(13.7)$ & $77.3 \%(12.0)$ & 0.15 \\
\hline Diabetic foot risk (SD) & 63,823 & $58.9 \%(22.1)$ & $62.6 \%(19.5)$ & 0.29 \\
\hline Podiatry referral (SD) & 6820 & $82.7 \%(19.9)$ & $79.2 \%(19.7)$ & 0.50 \\
\hline \multicolumn{5}{|l|}{ Lifestyle screening } \\
\hline Alcohol screening performed (SD) & 206,302 & $93.2 \%(3.9)$ & $93.6 \%(3.5)$ & 0.68 \\
\hline Alcohol F/U positive screen (SD) & 16,947 & $78.9 \%(20.7)$ & $81.6 \%(16.8)$ & 0.04 \\
\hline Tobacco counseling performed (SD) & 45,220 & $90.0 \%(12.9)$ & $89.2 \%(11.5)$ & 0.37 \\
\hline \multicolumn{5}{|l|}{ Immunizations } \\
\hline Influenza (overall) (SD) & 241,428 & $45.2 \%(8.8)$ & $45.9 \%(11.6)$ & 0.25 \\
\hline Influenza (18-64) (SD) & 97,639 & $34.8 \%(10.6)$ & $36.1 \%(15.4)$ & 0.08 \\
\hline Influenza $(>65)(\mathrm{SD})$ & 138,958 & $52.9 \%(10.1)$ & $53.2 \%(11.5)$ & 0.40 \\
\hline PPSV23 (SD) & 162,321 & $78.9 \%(13.4)$ & $77.0 \%(15.2)$ & 0.25 \\
\hline PCV13 (SD) & 138,178 & $78.4 \%(12.9)$ & $78.8 \%(12.9)$ & 0.90 \\
\hline Tdap (SD) & 241,428 & $67.3 \%(22.8)$ & $70.4 \%(20.7)$ & 0.33 \\
\hline \multicolumn{5}{|l|}{ Opiate management } \\
\hline Opioid urine screen (SD) & 7414 & $87.6 \%(14.3)$ & $88.4 \%\left(13 / 8 \_\right)$ & 0.31 \\
\hline Opioid consent (SD) & 7414 & $91.4 \%(12.3)$ & $90.5 \%(13.4)$ & 0.78 \\
\hline \multicolumn{5}{|l|}{ Continuity } \\
\hline Visit $<18$ months (SD) & 241,248 & $96.0 \%(2.5)$ & $96.5 \%(2.2)$ & 0.05 \\
\hline \multicolumn{5}{|l|}{ Miscellaneous } \\
\hline OEF/OIF post deploy screen (SD) & 25,031 & $88.0 \%(14.9)$ & $90.8 \%(12.8)$ & 0.18 \\
\hline HIV testing offered (SD) & 236,141 & $75.1 \%(21.9)$ & $77.6 \%(21.9)$ & 0.94 \\
\hline
\end{tabular}

*Adjusted for panel size, type of provider (MD vs. NP or PA), years since completion of training, status (staff vs. trainee), VA Center 
difference in offering testing for HIV, urine drug screening, or opiate consent among patients using chronic opiates, and in percentage of patients with regular follow-up or in the completion rates of a VA-specific screening for returning veterans from Operation Enduring Freedom or Operation Iraqi Freedom. There was no difference in performance on any of the measures by type of provider (MD/DO vs. NP vs. PA, $p>0.23$ for all measures) or trainee status (staff vs. trainee, $\mathrm{p}>0.37$ for all measures).

Using a more conservative $p$ value of 0.05 , women were $4.4 \%$ more likely to screen for potential hypoglycemia $(p=$ 0.006 ) and $3 \%$ more likely to follow up on screens that suggested risky alcohol behavior $(p=0.04)$.

\section{DISCUSSION}

In this cohort of VA primary care patients, there were no differences in overall quality or in the process and outcome measures for the 34 measures collected between male and female providers. Using a more lenient threshold of $p<0.05$, women providers had $4.4 \%$ higher screening rates for hypoglycemia in diabetic patients on hypoglycemic medications and $3 \%$ higher rates of following up on a positive screen for risky alcohol use obtained during the patient's check-in. These differences are unlikely to be clinically significant and may be a chance finding, given the number of comparisons.

While it is impossible from this cohort to explain the reason that previously reported differences in care provision have narrowed, there are a number of plausible explanations. Most previous studies are decades old and are based on chart audits from providers not using EHRs. Our providers work in a contemporary system with advanced clinical decision support and mature audit and feedback to providers about their performance on quality measures. This quality improvement package is a potential force that may have removed the variation between men and women PCPs observed previously. Audit and feedback have been demonstrated to improve performance. $^{32,}{ }^{33}$ In addition, the VA has adopted a patientcentered medical home (PCMH) approach to primary care which may reduce variation between men and women providers. ${ }^{34-37}$ Our study design cannot unpack the influence of these individual components, including the use of electronic reminders and quarterly feedback, the ability to create registries for patient conditions to identify which patients are not meeting the benchmark, or the influence of patient-centered medical homes.

In addition, while women providers have a more patientcentered communication style, interventional studies to improve communication have generally resulted in improved satisfaction and trust for both men and women providers, but have generally not improved disease-specific outcomes, such as diabetes or blood pressure control. ${ }^{38}$ Surprisingly, despite studies that have consistently shown women are more patientcentered, most studies show no differences in trust or satisfaction between men and women providers. ${ }^{2}$ It is possible that patient expectations for communication from men and women providers are different and that patients gravitate to providers that match their desired communication style. ${ }^{39}$

Our study has a number of limitations. First, the results depend on the accuracy of the VA's Performance Monitoring Program. These measures have been used in a number of studies comparing VA to non-VA care ${ }^{40-43}$ and are mostly widely accepted, validated, HEDIS measures. Many of the measure are objectively abstractable from the electronic record (tests ordered, drugs prescribed, immunizations given, HgbA1c level). However, other measures, for example, following up on risky alcohol screen results or providing tobacco counseling, are based on providers completing the EHR chart alert. It is possible that some PCPs may not document everything they say or may document things they did not really do. This would impact our findings, though it is unclear that these behaviors are more likely to happen with one or the other gender. Importantly, our study included outcome measures which are thought to be a proxy for good care, but do not encompass all the features for patient-centered care. Secondly, the VA's system of primary care and electronic medical records may limit generalizability, particularly to practices that do not have EHR capability. Third, the patient population was predominantly male; though our sample included 17,279 women, our results might not be generalizable to clinics with more balanced male-female patient ratios. Fourth, our sample is geographically limited to the upper Midwest. This may limit generalizability to health systems located in other parts of the country. Finally, we did not have patient-level data, so we could not assess the impact of patient-level factors, such as age, race, gender, or patient-provider gender concordance. We explored two models for adjusting, adjusting by site (the model we used), or hierarchal adjustment on providers by site. We found no differences in our results, and the former model was a poor fit. This, however, is no substitute for having patient-level data.

In conclusion, in contrast to several older studies, we found no differences in the quality of primary care by gender of the provider. Using a more conservative cut-point of $p=0.05$, women were more likely to screen for hypoglycemia and follow-up on positive screens for risky alcohol use, but the difference was small and likely due to chance, given the multiple comparisons. There was no difference in female gender-specific health screening, such as cervical and breast cancer screening, the measure most commonly found to be more likely to be performed by women providers in previous studies.

Corresponding Author: Jeffrey L. Jackson, MD, MPH; Zablocki VAMC, Milwaukee, WI, USA (e-mail: jjackson@mcw.edu).

Author Contribution All contributors are co-authors for the manuscript. 


\section{Compliance with Ethical Standards:}

This project was approved by our local IRB.

Conflict of Interest: The authors declare that they do not have a conflict of interest.

Disclaimer: The opinions expressed in this article reflect those of the authors and should not be construed in any way to be those of the US Government or the Department of Veterans Affairs.

\section{REFERENCES}

1. Bertakis KD, Franks P, Epstein RM. Patient-centered communication in primary care: physician and patient gender and gender concordance. J Womens Health. 2009;18(4):539-545.

2. Hall JA, Blanch-Hartigan D, Roter DL. Patients' satisfaction with male versus female physicians: a meta-analysis. Med Care 2011;49(7):611617.

3. Woodward CA, Hutchison BG, Abelson J, Norman G. Do female primary care physicians practise preventive care differently from their male colleagues? Can Fam Physician 1996;42:2370-2379.

4. Bertakis KD, Helms LJ, Callahan EJ, Azari R, Robbins JA. The influence of gender on physician practice style. Med Care 1995;33(4):407-416.

5. Cassard SD, Weisman CS, Plichta SB, Johnson TL. Physician gender and women's preventive services. J Women's Health 1997;6(2):199-207.

6. Kreuter MW, Strecher VJ, Harris R, Kobrin SC, Skinner CS. Are patients of women physicians screened more aggressively? A prospective study of physician gender and screening. J Gen Intern Med 1995;10(3):119-125.

7. Frank E, Harvey LK. Prevention advice rates of women and men physicians. Arch Fam Med 1996;5(4):215-219.

8. Franks P, Bertakis KD. Physician gender, patient gender, and primary care. J Womens Health. 2003;12(1):73-80.

9. Smith AW, Borowski LA, Liu B, et al. U.S. primary care physicians' diet, physical activity-, and weight-related care of adult patients. Am J Prev Med 2011;41(1):33-42.

10. O'Loughlin J, Makni H, Tremblay M, Karp I. Gender differences among general practitioners in smoking cessation counseling practices. Prev Med 2007;45(2-3):208-214.

11. Tabenkin H, Eaton CB, Roberts MB, Parker DR, McMurray JH, Borkan J. Differences in cardiovascular disease risk factor management in primary care by sex of physician and patient. Ann Fam Med 2010;8(1):25-32.

12. Lurie N, Slater J, McGovern P, Ekstrum J, Guam L, Margolis K Preventive care for women. Does the sex of the physician matter? N Engl J Med 1993;329(7):478-482.

13. Dominick KL, Skinner CS, Bastian LA, Bosworth HB, Strigo TS Rimer BK. Provider characteristics and mammography recommendation among women in their 40s and 50s. J Womens Health. 2003;12(1):61-71.

14. Ince-Cushman D, Correa JA, Shuldiner J, Segouin J. Association of primary care physician sex with cervical cancer and mammography screening. Can Fam Physician 2013;59(1):e11-18.

15. Reid RO, Friedberg MW, Adams JL, McGlynn EA, Mehrotra A. Associations between physician characteristics and quality of care. Arch Intern Med 2010;170(16):1442-1449.

16. Dahrouge S, Seale E, Hogg W, et al. A Comprehensive Assessment of Family Physician Gender and Quality of Care: A Cross-Sectional Analysis in Ontario, CanadaMed Care 2016;54(3):277-286.

17. Jackson JL, Chamberlin $\mathbf{J}$, Kroenke K. Gender and symptoms in primary care practices. Psychosomatics. 2003;44(5):359-366.

18. DesRoches CM, Campbell EG, Rao SR, et al. Electronic health records in ambulatory care-a national survey of physicians. N Engl $\mathrm{J}$ Med 2008;359(1):50-60.

19. James J. Pay-for-Performance. Health Affairs 2012.

20. Technology OotNCfHi. Office-Based Physician Electronic Health Record Adoption, "Health IT Quick-Stat \#50.". dashboard.healthit.gov/ quickstats/pages/physician-ehr-adoption-trends.php. Published 2019. Accessed 3 July 2019

21. Assurance NCfQ. Patient-Centered Medical Home. National Center for Quality Assurance. https://www.ncqa.org/programs/health-care-providers-practices/patient-centered-medical-home-pcmh/. Published 2019. Accessed 24 July, 2019.
22. Corrigan JM, Nielsen DM. Toward the development of uniform reporting standards for managed care organizations: the Health Plan Employer Data and Information Set (Version 2.0). Jt Comm J Qual Improv 1993;19(12):566-575.

23. Pham HH, Schrag D, Hargraves JL, Bach PB. Delivery of preventive services to older adults by primary care physicians. Jama. 2005;294(4):473-481.

24. Choo EH, Chang $\mathbf{K}$, Ahn $\mathbf{Y}$, et al. Benefit of beta-blocker treatment for patients with acute myocardial infarction and preserved systolic function after percutaneous coronary intervention. Heart. 2014;100(6):492-499.

25. Hennekens CH. Update on aspirin in the treatment and prevention of cardiovascular disease. Am J Manag Care 2002;8(22 Suppl):S691-700.

26. Vrecer M, Turk S, Drinovec J, Mrhar A. Use of statins in primary and secondary prevention of coronary heart disease and ischemic stroke. Meta-analysis of randomized trials. Int $\mathrm{J}$ Clin Pharmacol Ther 2003;41(12):567-577.

27. Whelton PK, He J, Appel $\mathbf{L} \mathbf{J}$, et al. Primary prevention of hypertension: clinical and public health advisory from The National High Blood Pressure Education Program. Jama. 2002;288(15):1882-1888.

28. Zauber AG, Winawer SJ, O'Brien MJ, et al. Colonoscopic polypectomy and long-term prevention of colorectal-cancer deaths. N Engl J Med 2012;366(8):687-696.

29. Abdulla J, Pogue J, Abildstrom SZ, et al. Effect of angiotensinconverting enzyme inhibition on functional class in patients with left ventricular systolic dysfunction-a meta-analysis. Eur J Heart Fail 2006;8(1):90-96

30. Navathe AS, Emanuel EJ, Bond A, et al. Association Between the Implementation of a Population-Based Primary Care Payment System and Achievement on Quality Measures in Hawaii. Jama. 2019;322(1):5768.

31. Benjamini YHY. Controlling the false discover rate: a practical and powerful approach to multiple testing. J R Stat Soc 1995;57(1):289-300.

32. Gardner LA, Snow V, Weiss KB, et al. Leveraging improvement in quality and value in health care through a clinical performance measure framework: a recommendation of the American College of Physicians. Am J Med Qual 2010;25(5):336-342.

33. Loeb JM. The current state of performance measurement in health care. Int J Qual Health Care 2004; 16 Suppl 1:i5-9.

34. Cordasco KM, Hynes DM, Mattocks KM, Bastian LA, Bosworth HB, Atkins D. Improving Care Coordination for Veterans Within VA and Across Healthcare Systems. J Gen Intern Med 2019;34(Suppl 1):1-3.

35. Forman J, Harrod M, Robinson C, et al. First things first: foundational requirements for a medical home in an academic medical center. $J$ Gen Intern Med 2014;29 Suppl 2:S640-648.

36. Greenstone CL, Peppiatt J, Cunningham $\mathbf{K}$, et al. Standardizing Care Coordination Within the Department of Veterans Affairs. J Gen Intern Med 2019;34(Suppl 1):4-6.

37. Piette JD, Holtz B, Beard AJ, et al. Improving chronic illness care for veterans within the framework of the Patient-Centered Medical Home: experiences from the Ann Arbor Patient-Aligned Care Team Laboratory. Transl Behav Med 2011;1(4):615-623.

38. Jackson JL. From the Editors' Desk: Why Does Not Improvement in Communication Lead to Improvement in "Hard" Outcomes? J Gen Intern Med 2019;34(6):779-780.

39. O'Malley PG; Becher D RG, Hanson JL, Jackson JL. Who's on First? In the chaos of decision making: a study of doctor, patient and objective ratings of shared decision making using directly observed encounters. Society of General Internal Medicine Annual Meeting; April 24-27, 2013, 2013; Denver, Colorado.

40. Trivedi AN, Matula S, Miake-Lye I, Glassman PA, Shekelle P, Asch S. Systematic review: comparison of the quality of medical care in Veterans Affairs and non-Veterans Affairs settings. Med Care 2011;49(1):76-88.

41. Anhang Price R, Sloss EM, Cefalu M, Farmer CM, Hussey PS. Comparing Quality of Care in Veterans Affairs and Non-Veterans Affairs Settings. J Gen Intern Med 2018;33(10):1631-1638.

42. Hedeen AN, Heagerty PJ, Fortney JC, Borowsky SJ, Walder DJ, Chapko MK. VA community-based outpatient clinics: quality of care performance measures. Med Care 2002;40(7):570-577.

43. Mencke NM, Alley LG, Etchason J. Application of HEDIS measures within a Veterans Affairs medical center. Am J Manag Care 2000;6(6):661-668.

Publisher's Note Springer Nature remains neutral with regard to jurisdictional claims in published maps and institutional affiliations. 